\title{
As palavras de um certo modo agrupadas e a fugacidade das coisas do mundo: aspectos da poesia de Adélia Prado
}

Claudia Campos Soares I UFMG

Com tão apressado vôo passa a rosa a carreira da vida, sendo nova pregadora cada dia da brevidade da nossa. Pe. Antônio Vieira. "Trigésimo sermão do Rosário"

Resumo: Este trabalho empreende uma discussão acerca de alguns aspectos da poesia de Adélia Prado. Partindo do poema "A rosa mistica", discute-se a forma como nessa poesia se apresenta a relação entre arte e natureza. Adélia Prado é uma escritora da identificação com o mundo. Seus poemas nascem de estímulos da realidade prosaica do cotidiano, que évalorizada como repositório de beleza e riqueza. Ela, entretanto, está marcada pela transitoriedade. Dai a necessidade de preservá-la da corrosão do tempo, função que é atribuida à poesia.

Palavras chave: Adélia Prado, arte e natureza, função da poesia

Em "A rosa mística", de Adélia Prado, relata-se um percurso em direção à poesia: são apresentadas, em seqüência temporal, as etapas de um 
processo que, iniciado com a visão de um objeto do mundo, culmina na realização de um poema, o primeiro que o eu lírico, poeta, escreveu. O poema é, portanto, revelador de uma experiência dos caminhos do poético e, ao mesmo tempo, reflexão metalingüística acerca das relações entre natureza e poesia.

Notações temporais demarcam as fases sucessivas do percurso, dividindo "A rosa mística" em três momentos. O primeiro deles, introduzido pelo "A primeira vez" que abre o poema, termina no sétimo verso; trata-se do momento em que se dá, diante de uma cesta de tomates e cebolas, o que é chamado de a primeira "consciência de uma forma":

A primeira vez

que tive a consciência de uma forma,

disse à minha mãe:

dona Armanda tem na cozinha dela uma cesta

5 onde põe os tomates e as cebolas;

começando a inquietar-me pelo medo

do que era bonito desmanchar-se,

O segundo, inicia-se no oitavo verso por um "até que" e termina no vigésimo nono:

até que um dia escrevi:

"neste quarto meu pai morreu,

10 aqui deu corda ao relógio

e apoiou os cotovelos

no que pensava ser uma janela

e eram os beirais da morte".

Entendi que as palavras

15 daquele modo agrupadas

dispensavam as coisas sobre as quais versavam,

meu próprio pai voltava, indestrutível.

Como se alguém pintasse

a cesta de d. Armanda

20 me dizendo em seguida:

agora podes comer as frutas.

Havia uma ordem no mundo,

de onde vinha?

E por que contristava a alma 
25

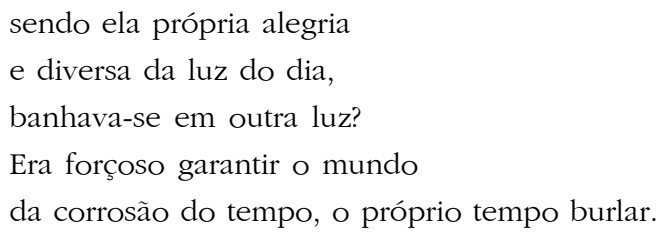

Trata-se de um segmento longo, no qual se poderia identificar uma subdivisão interna. Temos, no décimo terceiro verso, o primeiro ponto final desde o início do poema. Esse ponto marca também o fim da citação de parte do primeiro poema escrito pelo eu lírico, sinalizando o cumprimento de uma etapa decisiva do trajeto iniciado por ocasião da primeira "consciência de uma forma". Abre-se, então, espaço para uma nova inflexão em "A rosa mística": a passagem do discurso sobre a prática da escrita poética para o da reflexão sobre o objeto que dela resulta. Os versos que contemplam o discurso da ação (8-13) corresponderiam à primeira subdivisão desse segmento; os que contemplam a reflexão (14-29), à segunda.

A esses dois momentos, seguir-se-ia o último, iniciado pelo "então" do trigésimo verso. Aí retorna o plano da ação, voltado para a criação do primeiro poema, que continua sendo citado até seu fechamento. Na sequência, fecha-se também "A rosa mística" com um último verso.

30 Então prossegui: "neste quarto meu pai morreu...

Podes fechar-te, ó noite, teu negrume não vela esta lembrança".

Foi o primeiro poema que escrevi.

Há, portanto, uma progressão no poema, que indica as etapas de um processo. É importante ressaltar, entretanto, que somente a primeira delas tem efetiva distância cronológica das demais. O "até que", que separa o primeiro do segundo momento, se indica, por um lado, a relação de continuidade entre a tomada de "consciência da forma" e o ato de escrever os primeiros versos do poema inaugural, ${ }^{1}$ por outro não os vincula por meio da narração das etapas que

\footnotetext{
1. Nem mesmo a pontuação estabelece ruptura efetiva entre eles: a expressão adverbial, que inicia um novo momento na linha temporal do poema, não se separa do primeiro por nenhum sinal de pontuação de caráter conclusivo. Ao invés de um ponto, ou mesmo um ponto e vírgula, simplesmente uma vírgula.
} 
teriam intermediado as duas situações, deixando, ao mesmo tempo, implícita e indeterminada a conexão entre elas. A escrita do poema primeiro parece acontecer subitamente, indicando que se interpõe entre ela e a "consciência da forma" uma lacuna, um intervalo que pressupõe a ocorrência de acontecimentos relacionados ao processo e não descritos em "A rosa mística". As relações entre o primeiro e o segundo momentos do poema, portanto, pressupõem encadeamento, mas também descontinuidade.

Daí em diante, o processo desenvolve-se continuamente: da descoberta da poesia, passando pela reflexão sobre o objeto produzido, suas relações com a natureza, até a conclusão do poema. Assim, haveria em "A rosa mística" três tempos, correspondendo, cada um deles, a um momento da trajetória existencial e poética do eu lírico: o momento original, a todos anterior e de todos determinante, da primeira "consciência de uma forma"; o seguinte, em que é escrito o primeiro poema e em que o eu lírico compreende que "as palavras / daquele modo agrupadas / dispensavam as coisas sobre as quais versavam"; e, por fim, o último, a todos posterior, em que se situa o plano da experiência presente do eu lírico, que, ao relatar os caminhos do poema inaugural, escreve o poema que aqui se estuda.

Os versos 1-7, que correspondem à primeira parte do poema, são parte de um único período e colocam em foco um extenso e interconectado sistema de relações: os três primeiros versos disparam o mecanismo e o interesse do poema - a revelação do poético, que leva o eu lírico ao diálogo com a mãe; os versos 4 e 5 apresentam uma forma recortada do tecido do mundo (a cesta com tomates e cebolas); e os versos 6 e 7 introduzem uma inflexão subjetiva, por meio da qual o poeta expressa seu "medo/ do que era bonito desmanchar-se".

A expressão do temor do eu lírico, nos versos 6-7, separa-se dos versos anteriores por um ponto e vírgula, mas conecta-se a eles por uma relação de causa e efeito. O "medo/ do que era bonito desmanchar-se" é o sentimento responsável pela necessidade de expressão, para que a "forma" percebida se preserve no tempo. "Sentimento" é também o nome dado por Croce ao conteúdo emocional unificador de todas as imagens de um poema, responsável pela sua coerência interna. $^{2}$ Esse é também o papel do temor do sujeito lírico do poema que aqui se estuda, conforme pretende-se demonstrar.

2. CROCE. Breviário de estética, p. 50. 
O distanciamento da voz poética que se faz ouvir em "A rosa mística", em relação ao sujeito que teve a primeira experiência de uma "forma", permite chamar de "consciência" ao que, pelo modo como se apresenta no poema, mais se assemelharia a uma "intuição", nos termos em que a definiu também Benedetto Croce. O que é nomeado de "consciência da forma" tem origem em um "sentimento" e resulta em uma "expressão". Croce define intuição justamente como expressão de matéria subjetivada, "estado expressivo do espírito".3

Consciência e intuição são palavras carregadas de sentidos aparentemente muito diversos. No contexto do poema, entretanto, é possível aproximá-las. Em "A rosa mítica", o acontecimento primeiro, objeto do relato, é lembrança. A narração se faz da perspectiva de quem já empreendeu o percurso e alcançou seu ponto de chegada. O eu lírico rememora uma trajetória cumprida; portanto, entre o seu momento presente - o tempo do poema "A rosa mística" e o dos acontecimentos relatados interpõe-se a mediação das experiências vividas no intervalo. O distanciamento temporal permite-lhe, não somente relatar, mas também interpretar o vivido. Cumprido o percurso da poesia, o poeta já constituído pode ver o primeiro indício de manifestação de uma sensibilidade poética em seus desdobramentos posteriores. Nos versos 14-29, quando o sujeito lírico, depois de transcrever os primeiros versos do primeiro poema, reflete sobre o significado do seu ato e o objeto que dele resultou, realiza-se a "consciência da forma" enquanto tal, como percepção intelectual. Mas não antes. A expressão subjetivada do mundo (a fala que recorta do mundo a cesta de d. Armanda) não se caracteriza, ainda, pela preocupação com a elucidação racional do fenômeno, mas pela sua transformação em imagem poética. Até esse momento, não é, portanto, percepção intelectual, mas intuição. Só numa etapa posterior é que a intuição se tornou consciência, sob a forma de matéria de reflexão.

A imagem da cesta de tomates e cebolas em "A rosa mística" evoca outras imagens, recorrentes na história da arte ocidental. Ela carrega ressonâncias da pintura; é possível estabelecer paralelismos entre ela e certos aspectos característicos do gênero pictórico conhecido como natureza morta. Como acontece nesse tipo de pintura, a expressão da intuição do sujeito lírico em imagem confere estatuto de existência poética a objetos do cotidiano que, dispostos artificialmente no interior de um espaço doméstico, ganham destaque incomum.

3. CROCE. Breviário de estética, p. 58. 
Em "A rosa mística", estes objetos, os tomates e as cebolas, têm em comum o fato de serem ambos frutos da natureza, motivo dentre os mais recorrentemente utilizados em naturezas mortas (bem como as cestas que os contém). Os frutos da natureza vinculam-se simbolicamente à expressão do princípio da vida, de sua origem e eterna regeneração. A cebolas e tomates, Chevalier e Gheerbrant atribuem o poder de provocar "o sentimento de força vital", as "virtudes afrodisíacas" e a "virtude fecundante".

Entretanto, ao se apresentarem dispostos para o consumo num cesto de cozinha, exibem-se em sua pura materialidade de objetos destinados à morte iminente. Sua pintura ou descrição poética é que, de certa forma, paralisa o processo, imobilizando uma existência momentânea e fugaz em imagem onde a vida se retém e se conserva. É justamente o que diz o sujeito lírico de "A rosa mística", quando, após reescrever os primeiros versos do seu primeiro poema, significativamente sobre a morte do pai, compreende (enfim a "consciência da forma") a natureza dos "poderes" da expressão estética, que finalmente dominara:

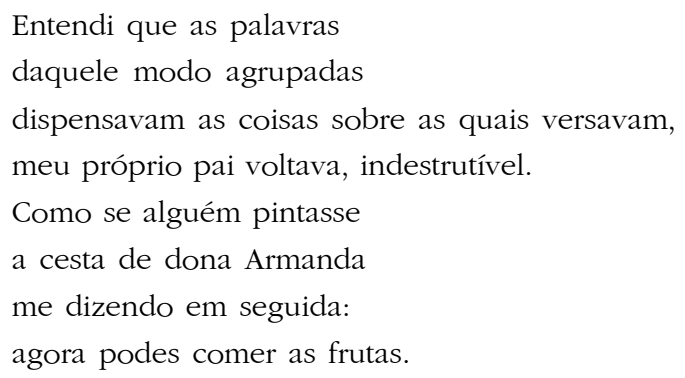

Articulando esses versos às demais imagens do poema está o mesmo sentimento motivador daquela espécie de natureza morta, que despertou no sujeito lírico, pela primeira vez, o "medo/ do que era bonito desmanchar-se". É este, como foi dito, com a mediação de uma categoria de Croce, o sentimento unificador das imagens do poema. Pintar o quadro e escrever poesia, como o eu lírico agora compreende, são formas de "burlar o tempo", que atendem a uma necessidade imperiosa, enunciada desta forma nos versos 28-29: "Era forçoso garantir o mundo / da corrosão do tempo". Fixado pela arte, aquilo que só muito provisoriamente

4. Chevalier; Gheerbrant. Dicionário de símbolos, p.217 e 887, respectivamente. 
poderia ser preservado em sua realidade física pode ser dispensado dessa empreitada vã e disponibilizar-se para uma experiência de outra natureza, que se dá na interação entre sujeito e objeto representado: a da fruição. Fixar o mundo em imagem - dar-lhe a realidade outra das "palavras de um certo modo agrupadas" ou de um quadro - permite, não somente retê-lo e fazer com que transcenda a contingência, que tudo destina à morte; mas também desfrutá-lo, usufruir dele em sua materialidade fugaz. O mundo fixado em imagem pode dispensar sua contrapartida no mundo dos sentidos e da experiência imediata: "Como se alguém pintasse / a cesta de d. Armanda / e dizendo em seguida: / agora podes comer as frutas."

Antes de prosseguir por esse caminho, entretanto, conviria voltar ao paralelismo da imagem do poema de Adélia Prado com as naturezas mortas. Lendo o poema "A maçã", de Manuel Bandeira, Davi Arrigucci Jr. faz considerações sobre o gênero que podem ser úteis também na discussão que aqui se desenvolve:

(...) São precisamente os objetos que se acham ao alcance da mão artificiais ou naturais - os que se convertem em motivos característicos da natureza-morta: a mesa com comida e bebida, as flores e as frutas, os livros, as louças, os utensílios domésticos etc. O olhar ganha para a reflexão e para a contemplação estética o que se destina ou se dispõe para o trabalho das mãos, para o uso diário. (...)

Espécie de ícone da vida privada, a natureza-morta (...) aparece como um espaço privilegiado para a reflexão sobre as complexas relações entre arte e realidade, entre estetização e natureza. Seu próprio modo de ser propicia uma permanente oscilação de ênfase entre o aspecto formal da convenção pictórica e a semelhança mimética com o tema representado. (...) Mais do que em outros gêneros, aqui é nítida a tensão entre os procedimentos de composição artística e a realidade objetiva do assunto.

Inicialmente, importa ressaltar que a reflexão acerca das relações entre arte e realidade é um dos motivos centrais do meta-poema "A rosa mística", questão que já foi aqui introduzida e à qual ainda se retornará posteriormente. Por ora importa somente ter isso em mente para ressaltar que a pequena imagem pictórico-poética do sujeito lírico está situada em seu justo espaço: a cesta de d. Armanda está na cozinha, um espaço interior, reservado à vida privada, em seu

5. ARRIGUCCI Jr. Humildade, paixão e morte, p.26. 
caráter comezinho e cotidiano; além disso, o objeto mimetizado pertence à categoria daqueles "que se acham ao alcance da mão" e que cumprem uma função prática na vida diária e doméstica. A imagem da cesta de tomates e cebolas paralisa a vida em seu caráter prosaico e banal, mas, ao fazê-lo, ganha para "a reflexão e a contemplação estéticas" o objeto até então destinado ao uso e ao consumo.

Como no poema "A maçã", na leitura de Davi Arrigucci Jr., em "A rosa mística" as "pequenas coisas", nas quais um olhar superficial não reconheceria nenhuma importância, elevam-se de seu "humilde cotidiano" à categoria de integrantes do "grande mundo", pois transcendem sua aparente insignificância para se alçarem ao sublime. Em Bandeira, Davi Arrigucci Jr. define a questão nos seguintes termos: "Para o poeta, o 'alumbramento', revelação simbólica da poesia, pode dar-se no chão do mais humilde cotidiano, de onde o poético pode ser 'desentranhado', à força da depuração e condensação da linguagem na forma simples e natural do poema." ${ }^{6}$

Adélia Prado encontrará o sublime no mundo a seu próprio modo, conforme se discutirá a seguir. Por enquanto, consideremos as semelhanças, tais como esta valorização do que só aparente e superficialmente pode ser considerado pequeno e desimportante. Daí decorre, em boa parte, a preferência de ambos os autores pelo prosaísmo dos temas e da maneira de abordá-los. Em Bandeira e Adélia Prado, esta descida (que é, na verdade, elevação) ao "grande mundo das pequenas coisas", como o chamou o crítico de Bandeira, é conteúdo programático, conforme (para citar apenas um exemplo, dentre os mais imediatamente perceptíveis em cada caso) o subtítulo de uma das partes que compõem O coração disparado, segundo livro de poemas publicado por Adélia Prado, "Qualquer coisa é a casa da poesia"; em Bandeira, as palavras do Itinerário de Pasárgada: "(...) a poesia está em tudo - tanto nos amores como nos chinelos, tanto nas coisas lógicas quanto nas disparatadas.."

6. ARRIGUCCI Jr. Humildade, paixão e morte, p. 15 - grifos do autor.

7. Os livros de poemas de Adélia Prado foram publicados conjuntamente em 1991. É esta Poesia Reunida a edição utilizada neste trabalho, à qual se referem, de agora em diante, os números de página que se seguem, entre parêntesis, à transcrição de poemas (ou trechos de poemas) da autora

8. BANDEIRA. Itinerário de Pasárgada, p. 34. 
A contrapartida formal desta opção temática é o tom de coloquialidade e o ritmo bastante próximo da linguagem oral, que caracterizam tanto a poesia de Adélia Prado como a de Bandeira. Em ambos os casos, a poesia confina com a prosa, já que realizada por uma sintaxe que não costuma privilegiar repetições rítmicas, mas sequências e continuidades, conforme se pode observar em "A rosa mística" a partir das discussões já realizadas neste trabalho. O poema de Adélia Prado é um exemplo privilegiado de organização formal onde a importância do sintagma parece ser maior que (ou tão importante quanto) a do paradigma, a despeito de tratar-se de um poema.

A este respeito, uma outra observação de Davi Arrigucci Jr. parece pertinente. Na origem da poesia de Bandeira, o crítico reconhece a transformação operada na retórica clássica pelo Cristianismo, que necessitava "veicular uma doutrina complexa e de caráter elevado mediante palavras simples, através do que Auerbach estudou nos termos do sermo humilis (discurso humilde), presente em todas as formas da literatura cristã da Antiguidade tardia e no início da Idade Média" . Em Mimesis, Auerbach assim se refere à origem destas formas: "(...) dos textos do Velho Testamento (...) surge um conceito de estilo elevado e de sublimidade diferente do que surge de Homero", este último muito mais próximo da regra de separação dos estilos que mais tarde se imporia e segundo a qual a descrição realista do cotidiano seria inconciliável com o sublime e só teria lugar no cômico ou, estilizada, no idílio. Ao contrário disso, ainda segundo Auerbach "(...) nos relatos do Velho Testamento, o sublime, trágico e problemático se formam justamente no caseiro e quotidiano". ${ }^{10}$ Conforme temos visto até agora, esta é também uma linhagem muito importante para a poesia de Adélia Prado; talvez os versos de "A rosa mística" identifiquem-se a esta tradição ainda mais diretamente que os do poema de Bandeira, o que se poderia confirmar atentando-se, agora, para algumas diferenças entre os dois poetas.

Nesse sentido, é importante observar que o "alumbramento" que o sujeito lírico do poema de Bandeira experimenta diante deste "grande mundo de pequenas coisas" ganha significado religioso muito específico em Adélia Prado, onde é vivenciado, conforme se verá, como epifania, revelação divina. O que se revela nas "pequenas pevides" da maçã de Bandeira "é a vida prodigiosa / Infinitamente".

9. ARRIGUCCI, Jr. Humildade, paixão e morte, p.38.

10. AUERBACH. Mimesis, p.19. 
Nas palavras de Davi Arrigucci Jr: "No infinitamente pequeno, se renova a vida da natureza, germina o futuro infinitamente. É o infinitamente pequeno que constitui a vida, princípio infinitamente grande que na maçã se exprime.” É notório que esta maçã esteja imantada de sentidos que em muito ultrapassam sua dimensão material e utilitária. É ainda Arrigucci Jr quem ressalta a transcendência da dimensão do natural no poema por força, principalmente, do adjetivo "prodigiosa":

Contra toda expectativa dentro da ordem natural, a vida brota com sua razão oculta na natureza. "A vida é um milagre", diz o poeta num outro verso. A maçã, em cuja intimidade ela se renova, misteriosamente, milagrosamente, a abriga, renovando o ciclo, contra o esperado. ${ }^{11}$

A vida vem envolta no fascínio do mistério e sua contrapartida, a revelação, o que reveste de uma gravidade própria do sagrado o objeto no qual tal "prodígio" se manifesta - nesse caso, uma maçã, já por si um tópico da tradição místico-religiosa ocidental. Trata-se, entretanto, de uma sacralidade mais difusa que a que emana do poema de Adélia Prado, porque mais dispersa em suas amplas possibilidades significativas: na imagem da fruta de Bandeira ecoam sentidos diversos, acumulados pela memória histórico-cultural - como o demonstra o próprio Davi Arrigucci Jr., ao analisar o simbolismo tradicional da fruta e suas possíveis relações com o poema objeto de sua leitura ${ }^{12}$ - mas nenhum deles se fixa de maneira definitiva e inequívoca. Em Adélia Prado, ao contrário, a sacralidade tem direção definida e é dada muito mais imediatamente. Pelo título, por exemplo: a Rosa Mística é o símbolo da Virgem Maria nas litanias cristãs. Além disso, o poema foi originalmente publicado no livro intitulado O Pelicano, outro símbolo cristão, figura do sacrifício de Cristo e sua ressurreição. ${ }^{13}$ Por se tratar de um aspecto configurador da visão de mundo da poesia de Adélia Prado, talvez seja oportuno pensar a religiosidade que se manifesta em "A rosa mística" a partir um olhar mais abrangente sobre sua obra em busca de fundamentos intertextuais que permitam ler, com mais propriedade, os aspectos religiosos implicados no título do poema.

Tal religiosidade é imediatamente identificável nos livros da autora: todos apresentam epígrafes extraídas de textos da Bíblia - que introduzem os

11. ARRIGUCCI Jr. Humildade, paixão e morte, p. 42.

12. ARRIGUCCI Jr. Humildade, paixão e morte, p. 35-39, principalmente.

13. Chevalier, J. Gheerbrant, A. Dicionário de símbolos, p. 705. 
livros e/ou demarcam suas subdivisões internas. Bagagem, o primeiro deles, além dessas citações, apresenta uma epígrafe como "recomendação" ao livro em geral: "Louvai ao Senhor, livro meu irmão, com vossas letras e palavras, com vosso verso e sentido, com vossa capa e forma, com as mãos de todos que vos fizeram existir, louvai ao Senhor." A esse texto, a autora acrescenta uma referência: "Da imitação do 'Cântico das criaturas' de São Francisco de Assis, a quem devo a graça deste livro." (p. 7)

A poesia que se inaugura em Bagagem apresenta-se, portanto, como cântico de louvação a Deus, cuja condição de possibilidade é o realizar-se de uma iluminação divina, uma "graça". Sob essa luz, o mundo se revela em glória, conforme o que enuncia um poema do livro já mencionado, O coração disparado, intitulado, justamente "Graça":

O mundo é um jardim. Uma luz banha o mundo.

A limpeza do ar, os verdes depois das chuvas, os campos vestindo a relva como o carneiro a sua lã, a dor sem fel: uma borboleta viva espetada.

Acodem as gratas lembranças:

moças descalças, vestidos esvoaçantes, tudo seivoso como a juventude, insidioso prazer sem objeto.

Insisto no vício antigo - para me proteger do inesperado gozo.

E a mulher feia? E o homem crasso?

Em vão. Estão todos nimbados como eu.

A lata vazia, o estrume, o leproso no seu cavalo

estão resplandecentes. Nas nuvens tem um rei, um reino,

um bobo com seus berloques, um príncipe. Eu passeio nelas, é sólido. O que não vejo, existindo mais que a carne.

Esta tarde inesquecível Deus me deu. Limpou meus olhos e vi: Como o céu, o mundo verdadeiro é pastoril. (p. 227)

Embora não se pretenda aqui estudar detidamente o poema, cumpre comentar alguns de seus aspectos que parecem relevantes à discussão em curso. O primeiro deles é a visão jubilosa do mundo que expressa; sua celebração, mais que da natureza, da criação. O mundo torna-se "jardim": sob os efeitos de uma "luz", uma tarde verdadeira (do "mundo verdadeiro") entrega-se, em visão de edênica maravilha, como dádiva sublime de Deus. O poeta, iluminado por essa luz (e, por isto, agraciado), celebra a experiência da fruição de uma tarde em 
estado de poesia e, ao fazê-lo, dá forma a uma visão epifânica do mundo, expressão do êxtase da unidade reconquistada entre homem e natureza, outra vez religados por meio de uma experiência que é, simultaneamente, religiosa e poética.

O que torna possível essa integração é a "visão de olhos limpos", capaz de alcançar, para além dos sentidos convencionalmente atribuídos às coisas, a sua natureza verdadeira, da perspectiva do poema. Vale ainda lembrar Croce cujas concepções, já se pôde demonstrar, têm com a poesia de Adélia Prado profundas afinidades - afirmando que a religião é forma de conhecimento da realidade: "religião é filosofia, filosofia em elaboração".

Os "olhos limpos" enxergam, portanto, a beleza verdadeira do mundo, sua ordem última; revelam-no, por isso, claro, harmonioso, explicado, compreensível, irradiando luz. É isso também o que sugere a descrição de desenvolvimento ordenado, cronologicamente seqüencial e gradativo, das etapas do percurso do poeta em "A rosa mística". Foi discutido também que a descrição tem seus lapsos, mas isto não invalida o argumento proposto: existe uma ordem no mundo, conforme o verso 22 , que a do poema acompanha, mas ela se banha "em outra luz", "diversa da luz do dia", conforme os versos 26-7. Trata-se da mesma imagem que aparece no poema "Graça", e demonstra que as explicações para o mundo que se oferecem na poesia de Adélia Prado encontram sua justificativa última nos desígnios insondáveis de Deus - pois a ordem do sagrado é inacessível ao homem, em toda a sua amplitude. ${ }^{15}$ O que dela se dá a revelar ocorre "em momentos de graça, infrequentíssimos", nas palavras de um outro meta-poema de Adélia Prado ("Antes do nome", p.22). Daí os intervalos de tempo entre o primeiro e o segundo momentos no poema, as súbitas irrupções das intuições e expressões - ou iluminações. Há sempre algo que se trama para além da consciência do sujeito e da aparência das coisas como as percebemos na vida cotidiana. A intuição capta a ordem divina somente quando Deus "limpa os olhos" dos homens para que ele possa ver o "mundo verdadeiro".

Nada (ou quase nada) no poema "Graça" ameaça a ordem radiosa do mundo vista por "olhos limpos". Imperfeições, os estigmas da "Queda", vão sendo enumerados num crescendo: a mulher feia, o homem crasso, o estrume, até

14. CROCE. Breviário de estética, p.42.

15. A falta de resposta à questão do verso 23 , sobre a origem desta ordem, parece sugerir, nesse contexto, sua atemporalidade, sua eternidade, o mistério da existência desde sempre e para sempre de Deus. 
chegar ao leproso, com a morte comendo-lhe as carnes; mas nada parece suficiente para abalar a visão jubilosa do mundo iluminado por Deus na insondável ordem de seus desígnios.

Pelo menos uma imagem, entretanto, causa certa estranheza, uma dissonância nessa expressão de um mundo perfeitamente harmonizado: trata-se da "borboleta viva espetada". Talvez se pudesse pensar que "espetá-la" pudesse ser também uma forma de fixar, para tornar perdurável, a beleza do mundo. Tal imagem, entretanto, carrega ressonâncias de sentidos menos positivos, como dor, sofrimento, aprisionamento. Por esse lado, é com a do leproso, cuja carne apodrece enquanto o homem ainda vive, que a imagem da borboleta mais se aproxima.

Imagens como essas são índices de que, apesar da glorificação do mundo que empreende, ou melhor, justamente por causa dela, um grande conflito está presente na poesia de Adélia Prado e pode ser percebido claramente em versos como estes, que finalizam o poema "Móbiles":

(...) A parreira verga de flores,

eu durmo inebriada,

achando pouca a beleza do mundo,

ansiando a que não passa nem murcha

nem fica alta, nem longe,

nem foge de encontrar meu duro olhar de gula.

A beleza imóvel,

a cara de Deus que vai matar minha fome. (p.248)

O que se percebe na poesia de Adélia Prado é que o valor simbólicoreligioso atribuído às coisas do mundo acaba, paradoxalmente, por aumentar o seu valor de realidade. São igualmente fortes, nesta poesia, a espiritualização e o apego às coisas do mundo (cuja beleza só é "pouca" porque não é eterna), conforme expressam as imagens que associam sensações corpóreas e/ou fisiológicas - como embriaguês, "ânsia", "olhar de gula", 'fome" - ao absoluto ou ao desejo, igualmente grave e solene, de que ele se manifeste.

Assim, o próprio apego à criação acaba por causar perturbações no canto de louvor ao criador. O conflito, nesse caso, provém, não da falta, mas do excesso de identificação com o mundo experimentado pelo sujeito lírico. O que "contrista a alma" é saber que a realidade "passa e murcha", pois caminha junto com o afã de experimentar o mundo como beleza e alegria uma aguda e desconfortante (às vezes desesperadora) consciência de sua fugacidade. 
O eixo e a roda: v. 19, n. 1, 2010

Em A rosa mística, recolocam-se as questões mencionadas:

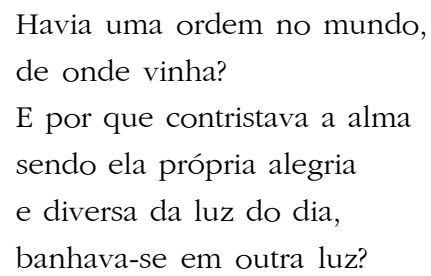

O sujeito lírico compreende a morte como parte da ordem divina que reconhece, mas não pode aceitar inteiramente. A voz que aqui se pergunta pela natureza dessa ordem sabe-a decorrente dos desígnios insuspeitáveis de Deus e, por isso, deveria aceitá-la tal como é: "luz", ainda que "outra", "diversa da luz do dia", sob os efeitos da qual as coisas do mundo manifestam-se com diversa aparência da que lhes é comum. O sujeito lírico nem sempre alcança fazê-lo, entretanto. A consciência da fugacidade da beleza do mundo (com o qual ele tanto se identifica) contrista-lhe a alma, provoca inquietações e medo (em um poema como "Móbiles", a consciência da fugacidade das coisas do mundo provoca um sentimento muito próximo do desespero, conforme a alta carga emocional de suas imagens), e é justamente esse o motor da poesia de Adélia Prado. Lembremos, novamente, Benedetto Croce: "a adaptabilidade, sempre imperfeita, e a fugacidade e mutabilidade das 'belezas naturais' justificam também o lugar inferior que a elas se atribui em confronto com as belezas produzidas pela arte." ${ }^{16}$ É por isto que o sujeito lírico de "A rosa mística" não pode recusar o apelo imperioso expresso em: "Era forçoso garantir o mundo/ da corrosão do tempo, o próprio tempo burlar." É então que ele pode terminar o poema sobre a morte do pai, convicto de que o negrume da noite que sempre se fecha sobre os homens não leva consigo o que deles se fixou, via memória, em imagens estéticas, carne incorruptível.

É nesse sentido também que pode ser lido o título do poema. Para isso, será precioso o auxílio do "Trigésimo Sermão do Rosário", de Vieira, no qual o pregador discursa sobre as excelências da Rosa Mística.

Vieira começa o sermão comparando a rosa natural à Rosa Mística, para realçar sua primazia sobre a primeira: "O místico por excelência não só consiste na semelhança que tem com o natural, senão nas vantagens com que o excede."17

16. CROCE. Breviário de estética, p. 61.

17. VIEIRA. Obras completas do Padre Antônio Vieira, p. 9. 
Continuemos com as palavras de Vieira: "(As rosas naturais) São geradas, como diz Plínio, in diem: porque no mesmo dia em que a vida lhes dá a cor, a fragrância lhe exala a vida. Pela manhã nascem, ao meio dia adoecem, à tarde morrem: e nem permanecem em si, nem no fruto, porque o não produzem." ${ }^{18}$ A Rosa Mística, ao contrário, permanece sobre todas as rosas, porque uma de suas excelências é ser "rosa com fruto", aquela que continua para além de si mesma. E o seu principal fruto é o filho de Deus. ${ }^{19}$

A Rosa Mística é também senhora dos mistérios do rosário, ao qual também a rosa deu o nome. Dentre eles, os "mistérios da glória" são os que mais interessam aqui: são os da "vista de Deus e bem-aventurança eterna". ${ }^{20}$ A rosa natural admoesta a brevidade da vida; a Rosa Mística remete à vida eterna.

O caminho que leva da rosa à Rosa Mística metaforiza a passagem do natural (belo, mas transitório e fugaz) para o espiritual, que, mística ou poeticamente, torna perdurável a beleza do mundo.

Pensando-se um poema como "Graça", por exemplo, em relação à grande divisão schilleriana da poesia, talvez fosse possível aproximá-lo da "poesia ingênua". ${ }^{21}$ Sob esse ponto de vista, talvez parecesse mais adequada a comparação com, ao invés de Bandeira, Jorge de Lima. Adélia Prado e o poeta alagoano são, ambos, poetas da identificação com o mundo; seus poemas nascem de estímulos da realidade a fim de celebrá-la (por isso os autores também têm em comum o gosto por imagens que remetem fortemente ao mundo das experiências), porque estão integrados ao mundo por uma visão religiosa.

Na poesia de Adélia Prado, entretanto, se vivem grandes questionamentos e dilaceramentos, como já foi dito. O eu lírico às vezes se desprega de sua unidade com o mundo e este despregar-se, apesar de não ser radical, é doloroso e problemático. Sob esse aspecto, Adélia Prado volta a se aproximar de Bandeira, embora o ritmo delicado de aproximação e distanciamento do mundo desse poeta se diferencie profundamente do modo fortemente emocional com que são expressos os sentimentos em boa parte dos poemas de Adélia Prado. Bandeira, se pudéssemos dizer assim, alumbra-se

18. Obras completas do Padre Antônio Vieira, p. 20.

19. Obras completas do Padre Antônio Vieira, p. 23.

20. Obras completas do Padre Antônio Vieira, p. 26.

21. SCHILLER. Poesia ingênua e sentimental. 
desencantadamente, e desencanta-se sem grandes arroubos, ao contrário da autora de "A rosa mística", que, em seus poemas, não se preocupa com comedimento e contenção.

Aproxima-os também, novamente distanciando-os da poesia ingênua, o programa e a reflexão, conforme já foi apontado aqui. Bandeira e Adélia Prado expressam em suas "Poéticas" e poemas metalingüísticos o distanciamento irreversível do homem em relação ao mundo e a necessidade de reconstituir, pela reflexão, a impressão de frescor da ingenuidade perdida. É por isso que, na poesia de Adélia Prado, é preciso se ter os "olhos limpos".

Adélia Prado e Bandeira são poetas sentimentais, cujo olhar não é mais ingênuo, mas desejaria ainda poder sê-lo. Em "A rosa mística", a poesia é programa de preservação da beleza do mundo; de restabelecimento, portanto, da ligação do homem com a realidade que o rodeia, de reconquista da unidade perdida. Aqui, a poesia é proposta como intuição e percepção, pensamento e imagem, o que atualiza, ainda nos últimos momentos do século XX, a discussão sobre o processo de integração da subjetividade e da reflexão na poesia iniciado no Romantismo.

The words in a certain order and the transience of worldly things: aspects of Adélia Prado's poetry

Abstract: This essay is devoted to a discussion of a few aspects of Adelia Prado's poetry. Starting with the poem A rosa mística, the discussion centers on the way the relationship between nature and art is presented. Her poems begin with motivations from prosaic everyday reality, which is then valued as a source of richness and beauty. It is, however, a reality marked by the transitory. Hence the need to preserve it from decay, a role that is to be fulfilled by poetry. Keywords: Adélia Prado, art and nature, the function of poetry 
Belo Horizonte, p. 1-167

$$
\text { Referências }
$$

ARRIGUCCI Jr, Davi. Humildade, paixão e morte: a poesia de Manuel Bandeira. São Paulo: Companhia das Letras, 1990.

AUERBACH, ERICH. Mimesis - a representação da realidade na literatura ocidental. São Paulo: EDUSP/Perspectiva, 1971.

BANDEIRA, Manuel. Poesia completa e prosa. 4.ed. Rio de Janeiro: Nova Aguilar, 1977.

Chevalier, J.; GHEerbrant, A. Dicionário de símbolos. 3.ed. Rio de Janeiro: José Olympio, 1990.

CROCE, Benedetto. Breviário de Estética. Aesthetica in nuce. São Paulo: Ática, 1997. PRADO, Adélia. Poesia reunida. São Paulo: Siciliano, 1991.

SCHILlER, Friedrich. Poesia ingênua e sentimental. São Paulo: Iluminuras, 1991.

VIEIRA, Antônio. Obras completas do Padre Antônio Vieira: Sermões, V. Porto, Lello e Irmão - Editores, 1993. 